\title{
Effects of Low-Level Laser Therapy on Tooth Socket Repair in Diabetic Male Rats: An Animal Study
}

\author{
A Peimani ${ }^{1}$, P Abedi ${ }^{* 2}$, H Hajjafari ${ }^{3}$ \\ 1- Department of Oral and Maxillofacial Surgery, Dental school, Rafsanjan University of Medical Sciences, \\ Rafsanjan, Iran, rafsanjan \\ 2- Student Research Committee, Rafsanjan University of Medical Sciences, Rafsanjan, Iran \\ 3- Student Research Committee, Rafsanjan University of Medical Sciences, Rafsanjan, Iran
}

\author{
ARTICLE INFO \\ Article History \\ Received: Apr 2020 \\ Accepted:May 2020 \\ ePublished: Jun 2020 \\ Corresponding author: \\ P Abedi,Student \\ Research Committee, \\ Rafsanjan University \\ of Medical Scienc- \\ es, Rafsanjan, Iran , \\ gpouya95@gmail.com
}

\begin{abstract}
Background and Aim: Extraction of teeth in diabetic patients can be followed by some complications such as delay in recovery of hard and soft tissues, dry socket, and increased risk of infection. This study investigated the impact of low-level laser therapy (LLLT) on tooth socket healing following extraction of maxillary molars in male rats.

Materials and Methods: In this experimental study, 30 male rats were divided into control and case groups. All rats were made diabetic with streptozotocin (STZ). After one week, the second molar of all rats was extracted. Helium-Neon (He-Ne) laser from a distance of $5 \mathrm{~mm}$ immediately irradiated tooth sockets in the experimental group for 120 seconds, which was continued until the third day. All the rats were sacrificed on days 3, 7, and 14 after the extraction in both groups for pathological evaluation of the amount of granulation tissue, angiogenesis, and the newly formed bone trabeculae, fibroblasts, macrophages, neutrophils, and lymphocytes. The results were statistically analyzed using Kruskal-Wallis test and one-way analysis of variance (ANOVA).

Result: LLLT could increase angiogenesis until day three $(\mathrm{P}=0.009)$, reduce the number of lymphocytes after day fourteen $(\mathrm{P}=0.001)$, increase the number of fibroblasts and neutrophils $(\mathrm{P}<0.05)$, reduce the extent of granulation tissue during the study $(\mathrm{P}<0.05)$, and elevate the extent of bone trabeculae after day fourteen $(\mathrm{P}=0.001)$.

Conclusion:The results indicated that low-level He-Ne laser therapy could reduce inflammation and accelerate the wound healing process in diabetic rats.

Keywords: Diabetes Mellitus, Low-Level Laser Therapy, Rats, Tooth Socket
\end{abstract}

J Res Dent Maxillofac Sci 2020;5(3):37-42.

\section{Introduction:}

Diabetes mellitus is a syndrome of impaired carbohydrate, fat, and protein metabolism, which is caused by a lack of insulin secretion or tissue sensitivity to insulin. Vascular disease, kidney damage, blindness, and atherosclerosis are more prevalent in diabetic patients than in the normal population. (1,2) $^{(120 v i o u s ~ s t u d i e s ~ h a v e ~ r e p o r t e d ~}$ that diabetes weakens the function of endothelial cells, which are in the vessel wall and take an important task in the normal functioning of blood vessels. ${ }^{(3)}$ Bone formation and amount of osteoids decrease in diabetics, which shows low bone turnover in them; ${ }^{(4)}$ diabetics show a $30-50 \%$ decrease in bone synthesis and implant osseointegration. ${ }^{(5)}$ Tooth extraction in diabetic patients also can cause some complications, including more infection risk, dry socket, and delayed wound healing. $(6,7)$ 
Laser therapy has had advantages in many medical and dental issues such as articular, cartilage, and bone problems in the past few decades. ${ }^{(8,9)}$ In dental applications, lasers have been applied for soft tissue operations such as biopsy and gingivectomy. ${ }^{(10)}$ Low-level laser therapy (LLLT) systems increase the synthesis of cytokine growth factors and apoptosis induction and also have a biomodulation effect on cells, which improves wound healing, and has analgesic, disinfecting, and anti-inflammatory effects. ${ }^{(11,12)}$ They also reduce pain and inflammation by increasing the activity of wound cells and enhance collagen synthesis. ${ }^{(13,14)}$

According to the literature, LLLT seems to promote vascularization and new bone formation to a limited extent in diabetic rats. ${ }^{(15)}$ Some studies also have indicated that LLLT enhances osteoblast density but it is not able to enhance new bone formation in diabetic male rats as it does in nondiabetics. ${ }^{(16)}$

Very few studies have examined the efficiency of LLLT in eliminating the complications induced by tooth extraction in diabetic patients. On the other hand, different methods have been used in such studies, many of which lack adequate information about the physical parameters of the laser used. Therefore, this study was conducted to experimentally evaluate the efficacy of LLLT in tooth socket repair in diabetic male rats.

\section{Materials and Methods:}

The experimental protocol has been approved by the Ethics Committee of Rafsanjan University of Medical Sciences (IR.RUMS.REC.1396.69). In this experimental study, 30 male Wistar rats, weighing 250-300g, were selected from the animal house of Rafsanjan Medical School. Before the test, the rats were examined by a veterinarian and evaluated for the surgical site and general health. Before surgery, the rats were kept under standard conditions in the animal laboratory of Rafsanjan Medical School for one week. All rats were injected intraperitoneally by streptozotocin (STZ; Sigma, MO, USA) dissolved in $50 \mathrm{mg} /$ $\mathrm{kg}$ of 0.1 citrate buffer to induce diabetes mellitus type 1. One week after STZ injection, the blood glucose of rats was measured by glucometers (Roche, Mannheim, Germany). Blood sugar $>250 \mathrm{mg} / \mathrm{dl}$ showed that the rats were diabetic.
Blood glucose levels were checked once a week during the test. Subjects were randomly divided into two groups of case and control (15 rats in each group) and were subjected to general anesthesia and injected with a combination of $100 \mathrm{mg} /$ $\mathrm{ml}$ of anesthetic/Ketamine (Irandarou, Tehran, Iran) and $100 \mathrm{mg} / \mathrm{ml}$ of Xylazine at a ratio of $1.9 \mathrm{cc} / 0.6 \mathrm{cc}$ for each $10 \mathrm{~g}$ weight of rats by intraperitoneal insulin syringes. Then, the upper right second molars of all rats were extracted. In the case group, after tooth extraction and bleeding control, the Plasmax IV, LHN 9709 Helium-Neon (He-Ne) laser device (KLD Biossistemas ${ }^{\circledR}$ ) was used. Tooth sockets were irradiated with He$\mathrm{Ne}$ laser with an optical output power of $100 \mathrm{~mW}$ and wavelength of $808 \mathrm{~nm}$ to a spot size area of $0.028 \mathrm{~cm} 2$. The energy density was $78.5 \mathrm{~J} / \mathrm{cm} 2$, and tooth sockets were irradiated at a distance of $5 \mathrm{~mm}$ from the target location for 120 seconds.

Laser therapy was performed for 120 seconds every day until the third day. In the control group, the laser probe was located the same as the experimental group conditions and without laser activation immediately after tooth extraction. After putting animals in a hot environment and following their recovery, they were kept in separate cages with free access to food and water in the same conditions.

On day 3 , the day of inflammation and proliferation phases, one-third of mice in each group (5 mice), on day 7 , the day of restriction and closure phases, half of the remaining mice in each group (5 mice), and on day 14, the time of bone tissue formation, the remaining animals in each group (5 mice) were sacrificed in compliance with the protocols recommended by the National Committee for the Protection of Animals used for Scientific Purposes. After detaching their maxilla, they were fixed in a $10 \%$ formalin solution for a week (Dr. Mojallali, Tehran, Iran). They were then placed in $4 \%$ Ethylenediaminetetraacetic acid (EDTA) solution at $40^{\circ} \mathrm{C}$ for bone tissue decalcification (Merck, Berlin, Germany). After 4 weeks, the softening of the bone tissue was checked by a scalpel. Samples were placed in a tissue processor (Sukura fine technical, Tokyo, Japan). They were soaked in paraffin 19 hours later and 5-micron sections were prepared from them using a microtome (SITE medical, Mainz, Germany). They were stained by hematoxylin 
and eosin staining and were pathologically examined by a pathologist, who was unaware of the sections of case and control groups on different days, under a light microscope at $400 \times$ magnification (Olympus BX51 microscope). The slides were assessed in terms of the extent of granulation tissue, angiogenesis, number of fibroblasts, macrophages, neutrophils, lymphocytes, and the amount of newly formed bone trabeculae and granulation tissue. The pathologist recorded the results in a checklist. Data were statistically analyzed using Kruskal-Wallis test to determine the effect of the groups and the evaluation days on the study variables, and one-way analysis of variance (ANOVA) was used for multiple comparisons. $\mathrm{P}<0.05$ was considered statistically significant.

\section{Result:}

LLLT on tooth sockets of all 30 diabetic rats could increase angiogenesis until day three $(\mathrm{P}=0.009)$, reduce the number of lymphocytes after day fourteen $(\mathrm{P}=0.001)$, increase the number of fibroblasts and neutrophils $(\mathrm{P}<0.05)$, reduce the extent of granulation tissue during the study $(\mathrm{P}<0.05)$, and increase the extent of bone trabeculae after day fourteen $(\mathrm{P}=0.001)$.

As shown in Figure 1, on the third day after the extraction, the mean number of blood vessels was $8.2 \pm 2.89$ in the control group and $14.2 \pm 5.24$ in the laser-treated group, indicating a significant difference between the groups $(\mathrm{P}=0.009)$.

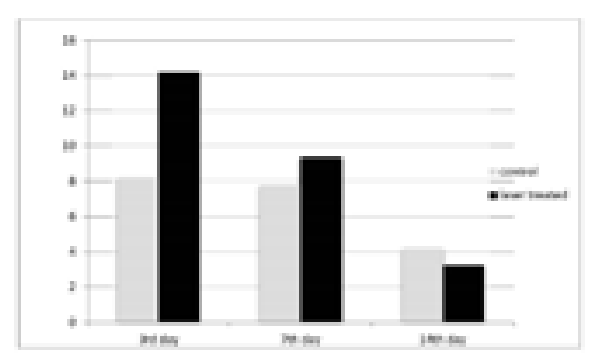

Figure 1. Mean number of newly formed vessels in both groups on days 3,7 , and 14

As indicated in Fig. 2, the number of neutrophil cells was significantly higher 3,7 and 14 days after extraction in comparison with laser treated group (P-value $<0.05)$.

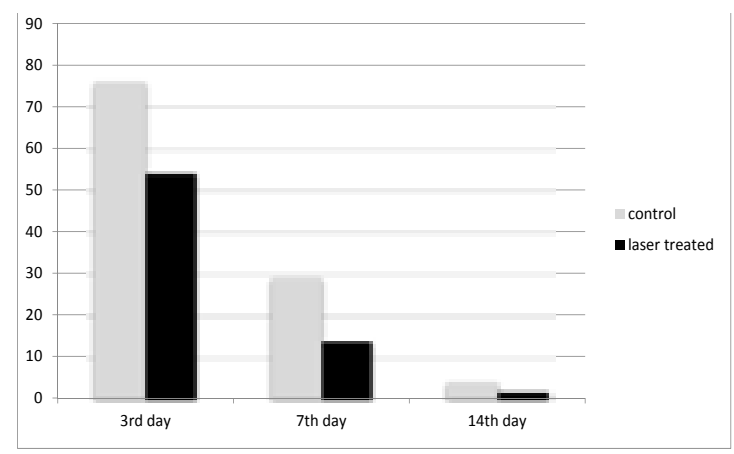

Fig 2. Mean number of newly formed neutrophils in both groups on days 3,4 , and 14

Figure 3 indicates no significant difference between the laser-treated and control groups in the number of lymphocyte cells 3 and 7 days after surgery $(\mathrm{P}=0.09)$. However, there was a significant reduction in the laser-treated group on day $14(\mathrm{P}=0.001)$.

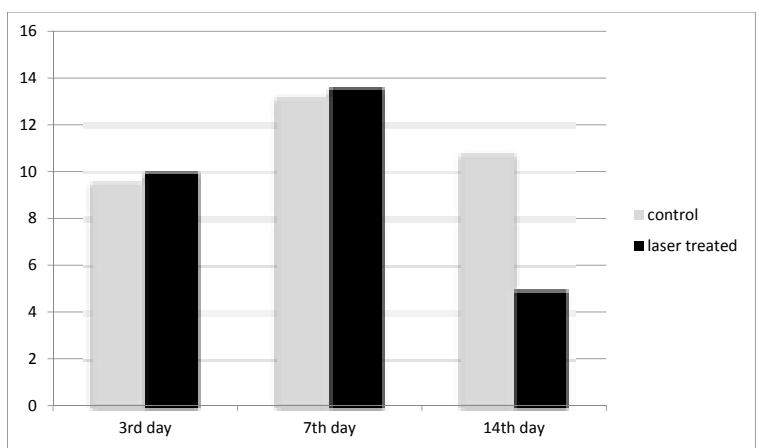

Fig 3. Mean number of newly formed lymphocytes in both groups on days 3,7 , and 14

Figures 4 and 5 also show a significant difference between the laser-treated and control groups in the number of macrophages and fibroblasts on day 3 . 


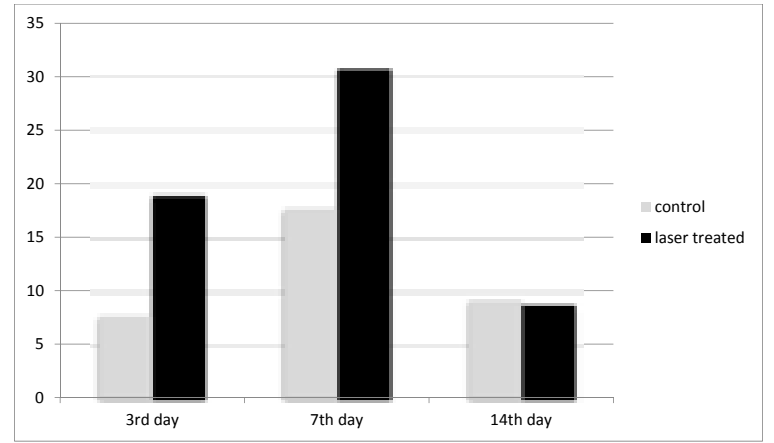

Fig 4. Mean number of newly formed macrophages in both groups on days 3,7 , and 14

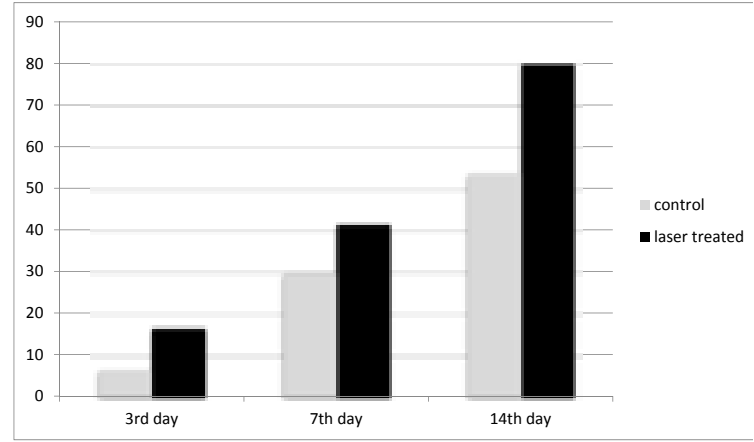

Fig 5. Mean number of newly formed fibroblasts in both groups on days 3,7, and 14

As shown in Figure 6, there is no significant difference between the control and laser-treated groups in the extent of granulation tissue 3 and 7 days after surgery $(\mathrm{P}=0.08)$.

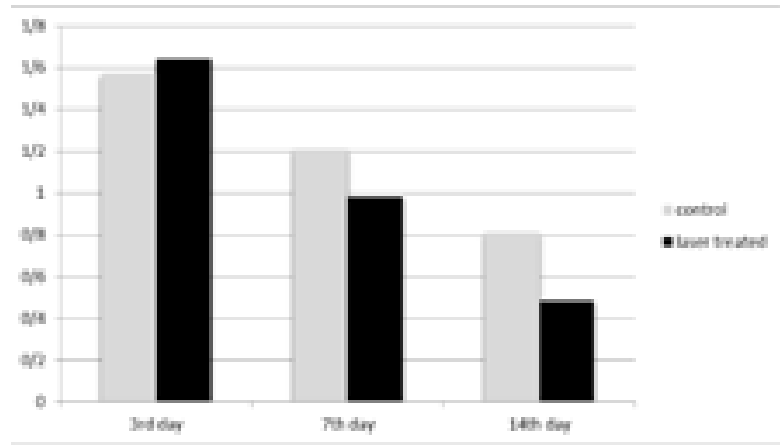

Fig 6. Mean extent of newly formed granulation tissue in both groups on days 3,7 , and 14
Interestingly, however, the mean extent of granulation tissue was significantly less in the laser-treated group than in the control group on day $14(\mathrm{P}<0.005)$.

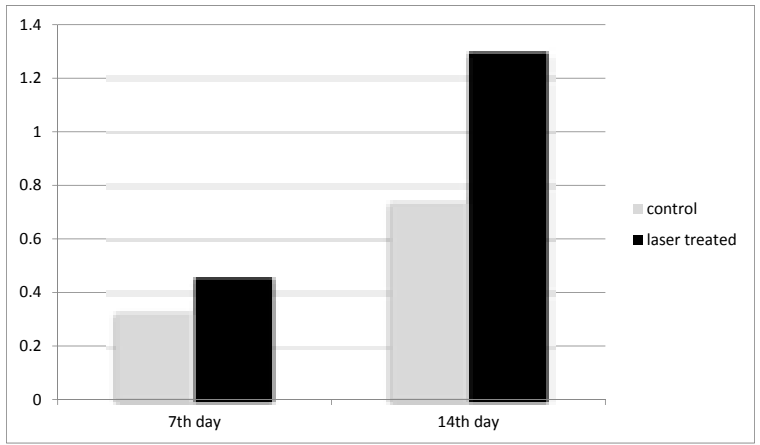

Fig 7. Mean number of newly formed trabeculae in both groups on days 7 and 14

Due to the lack of bone formation on day 3, the extent of trabecular bone was studied on days 7 and 14 . The extent of trabecular bone was significantly less in the control group than in the lasertreated group (Figure 7; $\mathrm{P}=0.001$ ).

\section{Discussion:}

The prevalence of diabetes, as one of the most common diseases in the world, has been reported to increase, especially in less developed countries. ${ }^{(17)}$ Therefore, treatments should be modified to have few complications due to diabetes; LLLT can be a way to reduce complications after tooth extraction. As clinical trials cause limitations in the method of study, male rats were used as subjects. STZ causes necrosis in the $\beta$-cells of the pancreas and causes type 1 diabetes; ${ }^{(18)}$ it was used to induce diabetes in the present study. ${ }^{(19)}$ This study showed that the application of $\mathrm{He}-\mathrm{Ne}$ laser $(100 \mathrm{~mW}, 808 \mathrm{~nm})$ in tooth socket could enhance bone formation and wound healing.

LLLT can affect cell proliferation and collagen synthesis, decrease the hypoxia caused by damage, and induce growth factor release. ${ }^{(20)}$ On the other hand, the efficacy of LLLT relies upon factors such as wavelength, frequency, power, spot size, and total treatment time. ${ }^{(21)}$ The results of the present study showed that using LLLT until day 3 could significantly increase angiogenesis although the differences were not significant on days 7 and 14. Other studies have also report- 
ed an increase in angiogenesis in the laser-treated groups. ${ }^{(22-24)}$ Yildirimturk et.al ${ }^{(15)}$ also applied GaAl-As ( $820 \mathrm{~nm}, 0.5 \mathrm{~W}$, three times a week) to diabetic animals and observed an increase in blood vessel counts.

The present study showed that fibroblast formation in the laser group was higher than in the control group. The same results were obtained by Ustaoglu et al, who determined the effects of LLLT on wound healing at the site of the human free gingival graft (FGG). They concluded that LLLT enhanced wound healing at the FGG donor site and preserved tissue thickness at palatal donor sites. ${ }^{(25)}$ Also, Eissa and Salih ${ }^{(24)}$ reported that lasers enhance wound healing in diabetic rats and turn down the healing time to the half although the method and procedure they applied were different (He-Ne laser at a wavelength of $632.8 \mathrm{~nm}$ with a power density of $4.0 \mathrm{~mW} / \mathrm{cm} 2$, five times a week). This finding was consistent with the results of previous studies, ${ }^{(14)}$ which can be due to different laser parameters and also soft tissue repair conditions.

The use of laser could decrease the number of neutrophils until day 14, indicating a significant reduction. Using laser increased the number of lymphocytes and macrophages on day 3 but the mean number of these cells was lower in the laser group than in the control group on day 14 , which can indicate the effect of laser on reducing the course of wound inflammation. Rabelo et $\mathrm{al}^{(26)}$ also reported that LLLT reduced wound inflammation. The cited study showed that the use of He-Ne laser at a $634.8 \mathrm{~nm}$ wavelength with an output power of $15 \mathrm{~mW}$ accelerates wound healing by decreasing inflammatory cells in both diabetic and non-diabetic groups in comparison with the control group. According to Alves et al (27), LLLT (arsenide and aluminum gallium-type diode lasers) with an output power of $50 \mathrm{~mW}$ was more efficient in modulating inflammatory cells (macrophages and neutrophils), showing a reduction in the inflammatory process.

The mean extent of trabecular bone on days 7 and 14 was higher in the laser group than in the control group. Similar to these results, Oliveira et al ${ }^{(28)}$ reported an increase of $31-58 \%$ in the survival rate of osteoblasts irradiated by $\mathrm{He}-\mathrm{Ne}$ laser; they concluded that osteoblastic proliferation and maturation increases as the osteogenic mark- ers elevate. Diker et. al ${ }^{(16)}$ reported that the application of Gallium-Aluminum-Arsenide (GaAlAs) diode laser at the wavelength of $808 \mathrm{~nm}$ with an optical output of $100 \mathrm{~mW}$ enhanced osteoblast density but was not able to enhance new bone formation, which shows that different irradiation parameters can affect the treatment procedure and the result of the treatment. Yildirimturk et al ${ }^{(15)}$ applied GaAlAs laser at the wavelength of $820 \mathrm{~nm}$ on animals with STZ-induced diabetes, which promoted vascularization and new bone formation. The results of the present study and similar studies indicate the positive role of LLLT in tooth socket repair to different extents because of different laser parameters.

\section{Conclusion:}

The results of this study support the idea that LLLT can reduce inflammation after tooth extraction and accelerate the bone healing process in diabetic male rats.

\section{Acknowledgements:}

This study was conducted with the financial support provided by Rafsanjan University of Medical Sciences.

\section{References:}

1.Powers A. Harrison's Principles of Internal Medicine, 18e ed. New York, NY, The McGrawHill Companies Inc., 2013:2968-3002.

2.Association AD. Diagnosis and classification of diabetes mellitus. Diabetes Care. 2014 Jan;37(Supplement 1):S81-90.

3.Shi Y, Vanhoutte PM. Macro- and microvascular endothelial dysfunction in diabetes. J Diabetes. 2017 May;9(5):434-449.

4.He H, Liu R, Desta T, Leone C, Gerstenfeld LC, Graves DT. Diabetes causes decreased osteoclastogenesis, reduced bone formation, and enhanced apoptosis of osteoblastic cells in bacteria stimulated bone loss. Endocrinology. 2004 Jan;145(1):447-52.

5.Shin SH, Kim JR, Park BS. Bone formation around titanium implants in the tibiae of streptozotocin-induced diabetic rats. J Korean 
Assoc Maxillofac Plast Reconstr Surg. 2000 Sep;22(5):522.

6.Rosenberg CS. Wound healing in the patient with diabetes mellitus. Nurs Clin North Am. 1990 Mar;25(1):247-61.

7.Power DJ, Sambrook PJ, Goss AN. The healing of dental extraction sockets in insulin-dependent diabetic patients: a prospective controlled observational study. Aust Dent J. 2019 Mar;64(1):1116.

8.Wickenheisser VA, Zywot EM, Rabjohns EM, Lee HH, Lawrence DS, Tarrant TK. Laser Light Therapy in Inflammatory, Musculoskeletal, and Autoimmune Disease. Curr Allergy Asthma Rep. 2019 Jul 2;19(8):37.

9.Sella VR, do Bomfim FR, Machado PC, da Silva Morsoleto MJ, Chohfi M, Plapler H. Effect of low-level laser therapy on bone repair: a randomized controlled experimental study. Lasers Med Sci. 2015 Apr;30(3):1061-8.

10.Walsh LJ. The current status of low level laser therapy in dentistry. Part 1. Soft tissue applications. Aust Dent J. 1997 Aug;42(4):247-54.

11.Mesquita-Ferrari RA, Martins MD, Silva JA Jr, da Silva TD, Piovesan RF, Pavesi VC, Bussadori SK, Fernandes KP. Effects of low-level laser therapy on expression of TNF- $\alpha$ and TGF- $\beta$ in skeletal muscle during the repair process. Lasers Med Sci. 2011 May;26(3):335-40.

12.Sussai DA, Carvalho Pde T, Dourado DM, Belchior AC, dos Reis FA, Pereira DM. Low-level laser therapy attenuates creatine kinase levels and apoptosis during forced swimming in rats. Lasers Med Sci. 2010 Jan;25(1):115-20.

13.Ferreira DM, Zângaro RA, Villaverde $A B$, Cury Y, Frigo L, Picolo G, Longo I, Barbosa DG. Analgesic effect of He-Ne $(632.8 \mathrm{~nm})$ low-level laser therapy on acute inflammatory pain. Photomed Laser Surg. 2005 Apr;23(2):177-81.

14.de Jesus JF, Spadacci-Morena DD, Rabelo ND, Pinfildi CE, Fukuda TY, Plapler H. Lowlevel laser therapy on tissue repair of partially injured achilles tendon in rats. Photomed Laser Surg. 2014 Jun;32(6):345-50.

15.Yildirimturk S, Sirin Y, Soluk Tekkesin M, Gurler G, Firat D. The effects of low-level laser therapy on the healing of bone defects in streptozotocin-induced diabetic rats: A histological and morphometric evaluation. J Cosmet Laser Ther.
2017 Nov;19(7):397-403.

16.Diker N, Aytac D, Helvacioglu F, Dagdelen C, Oguz Y. Evaluation of the Effects of Low-Level Laser Therapy on Diabetic Bone Healing. J Craniofac Surg. 2019 Oct;30(7):1994-1998.

17.NCD Risk Factor Collaboration (NCD-RisC). Worldwide trends in diabetes since 1980: a pooled analysis of 751 population-based studies with 4.4 million participants. Lancet. $2016 \mathrm{Apr}$ 9;387(10027):1513-1530.

18.Kumar S, Singh R, Vasudeva N, Sharma S. Acute and chronic animal models for the evaluation of anti-diabetic agents. Cardiovasc Diabetol. 2012 Jan 19;11:9.

19.Jiao H, Xiao E, Graves DT. Diabetes and Its Effect on Bone and Fracture Healing. Curr Osteoporos Rep. 2015 Oct;13(5):327-35.

20.Chen MH, Huang YC, Sun JS, Chao YH, Chen $\mathrm{MH}$. Second messengers mediating the proliferation and collagen synthesis of tenocytes induced by low-level laser irradiation. Lasers Med Sci. 2015 Jan;30(1):263-72.

21.Coluzzi DJ, Parker SP. Lasers in dentistrycurrent concepts: Springer; 2017 Sep.

22.Cury V, Moretti AIS, Assis L, Bossini P, de Souza Crusca J, Neto CB, et al. Low level laser therapy increases angiogenesis in a model of ischemic skin flap in rats mediated by VEGF, HIF$1 \alpha$ and MMP-2. J Photochem Photobiol B. 2013 Aug 5; 125: 164-70.

23.de Medeiros ML, Araújo-Filho I, da Silva EM, de Sousa Queiroz WS, Soares CD, de Carvalho MG, Maciel MA. Effect of low-level laser therapy on angiogenesis and matrix metalloproteinase-2 immunoexpression in wound repair. Lasers Med Sci. 2017 Jan;32(1):35-43. 24. E is s a M, Salih WHM. The influence of low-intensity $\mathrm{He}-\mathrm{Ne}$ laser on the wound healing in diabetic rats. Lasers Med Sci. 2017 Aug;32(6):1261-7.

25.Ustaoglu G, Ercan E, Tunali M. Low-Level Laser Therapy in Enhancing Wound Healing and Preserving Tissue Thickness at Free Gingival Graft Donor Sites: A Randomized, Controlled Clinical Study. Photomed Laser Surg. 2017 Apr;35(4):223-30.

26.Rabelo SB, Villaverde AB, Nicolau R, Salgado MC, Melo Mda S, Pacheco MT. Comparison between wound healing in induced diabetic and nondiabetic rats after low-level laser therapy. Photomed Laser Surg. 2006 Aug;24(4):474-9. 
27.Alves AC, Vieira R, Leal-Junior E, dos Santos S, Ligeiro AP, Albertini R, Junior J, de Carvalho P. Effect of low-level laser therapy on the expression of inflammatory mediators and on neutrophils and macrophages in acute joint inflammation. Arthritis Res Ther. 2013;15(5):R116.

28. Oliveira FA, Matos AA, Santesso MR, Tokuhara CK, Leite AL, Bagnato VS, et al. Low intensity lasers differently induce primary human osteoblast proliferation and differentiation. J Photoch Photobio B. 2016 Oct;163:14-21. 